\title{
ESTUDO DA NORMALIDADE PSICOLÓGICA
}

\author{
Iracy Doyle *
}

Estamos mais preocupados em compreender a normalidade, em fixar o seu conceito, do que pròpriamente em definí-la. Em sua essência complexo, o problema seria prejudicado por uma definição que procurasse fixá-lo em palavras, desde que se trata, na realidade, de um conceito essencialmente dinâmico. Nessas condições, a definição não auxiliaria em nada a compreensão do assunto. 0 que importa sôbre tudo é o conhecimento dos fatôres a tomar em consideração quando falamos em normalidade, pois dêles depende a limitação do conceito e a base de qualquer tentativa definidora.

A etimologia da palavra não nos traz qualquer auxílio: normalidade vem do grego norma, que significa medida, com a acepção de perfeição, de máximo, de protótipo, que não corresponde ao uso atual da palavra.

Por enquanto, deve ficar estabelecido o caráter relativo da normalidade, que nada tem de único e universal; o conceito em si representa uma série de realidades contingentes que o fazem mudar de aspecto, adquirir várias formas e acep̧̧ões, conforme o ângulo pelo qual o encaramos. Em relação ao homem, distinguimos um aspecto orgânico, um aspecto fisiológico, e um aspecto psicológico da normalidade; é êste último que nos interessa no momento, embora os três aspectos guardem relações entre si.

A variedade dos critérios com que tem sido abordado o problema da normalidade psicológica serve principalmente para indicar a sua complexidade, sem oferecer uma orientação realmente útil que nos permita compreender a normalidade e diagnosticá-la, o que é, às vêzes, tarefa do psiquiatra.

Seu caráter dinâmico e a elasticidade dos seus limites explicam em grande parte as dificuldades com que tropeçam os que tentam definí-la e delimitá-la de maneira concreta e categórica. Chega-se à conclusão de que não é possível situar a normalidade em um ponto fixo, em um nível constante, em uma medida matemática, mas que, ao contrário, temos que aceitar uma ampla zona com várias faixas de diferentes tonalidades. Dois indivíduos podem apresentar estruturas psicológicas que não permitem uma superposição, e nem por isso deixarão de merecer o diagnóstico de normali. dade. Estamos nos recordando no momento de uma senhora que nos trouxe o filho de 18 anos para observação psicológica, com o seguinte preâmbulo: "Eu mesma não sei se meu filho precisa de tratamento, mas achei prudente trazê-lo para ouvir a sua opinião, porque êle é diferente do irmão, e eu

* Docente-livre de Psiquiatria na Fac. Med. Univ. do Brasil (Rio de Janeiro). Diretora da Clínica de Repouso Tijuca. Ex-assistente da Johns Hopkins University. Graduada pelo William Alanson White Institute of Psychiatry. 
acho mais natural o modo pelo qual o outro se comporta no meio social". A análise da estrutura caracterológica revelou uma boa organização do jôyo de fôrças psicológicas orientadoras da conduta explícita e implícita, ausência de sintomas e de ansiedade neurótica; chegamos mesmo à conclusão de que se tratava de um adolescente extraordinàriamente inteligente, capaz, honesto, com ideais construtivos capazes de serem realizados por êle, atendendo às suas qualidades potenciais, apenas não grande apreciador das futilidades sociais e menos loquaz do que o irmão. No caso vertente ficou apurado que justamente o filho mais apreciado era realmente o que precisava de tratamento, pois a sua grande atividade era um recurso que usava para escoar um pouco da sua ansiedade.

Não se pense tampouco que as fronteiras da no:malidade podem ser traçadas com absoluta nitidez. Principalmente depois que o pensamento dinâmico penetrou a psicologia normal e patológica, e as investigações diag. nósticas não se limitam mais às aparências do comportamento explícito, todos os autores começam a acentuar a artificialidade da separação nítida entre a normalidade e a anormalidade psicológica. Entretanto, com tôdas estas reservas, admitimos a realidade do homem normal, que não pode e não deve ser confundido com o anormal e o doente, a menos que se incorra em uma verdadeira ilusão, conseqüência da confusão de valores.

\section{CRITERIOS DE APROXIMAR O PROBLEMA}

$\mathrm{Na}$ impossibilidade de analisar, dentro dọs limites dêste trabalho, os diferentes critérios propestos até o momento para a definição e estudo da normalidade, referiremos apenas algumas das limitações propostas pelos representantes dos diferentes critérios. Aliás, a adoção de um critério parcial tem a desvantagem de fragmentar o problema, con sacrifício evidente da harmonia do conjunto.

De acôrdo com o critério normativo, o homem normal seria o tipo perfeito, o arquetipo humano. Portanto, tratar-se-ia de umı abstração. Dentro do critério estatístico, chama-se normal ao tipo de homem mais freqüente. Na nossa cultura a maior frequêencia corresponderia a tipos indiscutìvelmente coartados. Dentro do critério clínico, o homem normal seria o homem sem sintomas. $O$ critério constitucionalista estabelece a igualdade "homem normal" = "estrutura genotípica normal". Se adotássemos o critério sociológico, chamaríamos de nornal o homem que em seu meio encarna melhor o tipo convencional da cultura, o que mais concorda com o espírito da época, e se adapta às exigências do ambiente. Dentro do critério criminológico, normal è o homem que não transgride as leis. Finalmente, o critério médico-legal fala em normalidade no caso em que o indivíduo é capaz de dirigir civilmente as suas ações e pode ser imputado responsável pelos seus atos.

Dentro do critério psicanalítico não se fala em normalidade. E' preciso não esquecer que a psicanálise teve por base as observações de Freud 
no seu trabalho com neuróticos. $\mathrm{O}$ fato indiscutível de que no meio social a neurose seja uma ocorrência relativamente freqüente, de tal modo que rnesmo fora do consultório Freud pudesse verificar comportamentos que não diferiam muito da conduta dos seus pacientes, deve ter concorrido para que a tendência indutiva do grande mestre o levasse a postular, por generalização, a universalidade da condição neurótica. A grande difusão da psicanálise, que trouxe incontestàvelmente à medicina psicológica um método para compreensão dos desvios da normalidade e seu tratamento, fêz com que neste século assistíssemos a uma verdadeira avalanche de livros versando sô. bré a psicologia normal, neuroses e psicoses, no seu aspecto dinâmico, a tal ponto que se chegou a perder a perspectiva da normalidade psicológica, atin. gindo-se o extremo de não se usar a palavra normalidade psicológica, ou empregá-la com muito cuidado, assinalada de aspas...

0 anseio de precisar o conceito de homem normal remonta aos tempos clássicos. Aristóteles pensou encontrar uma fórmula, na base dos valores prototípicos da humanidade, e aproximou a normalidade da perfeição. Pla. tão disse que o homem normal é aquêle "que possui um organismo suscetível de compreender a noção do que é justo; anormal é o que não se pode adaptar a esta compreensão, à educação e à instrução, sem as quais a vida social se torna impossível". Pascal tropeçou no caráter paradoxal do homem, assustou-se com i difusão das neuroses, e chegou a escrever: "Les hommes sont si necéssairement fous, que ce serait être fou par une autre tour de folie de n'être pas fou'.

Para muitos filósofos, sociólogos e literatos modernos, a normalidade eqüivale à mediocridade, e é caricaturada como algo de que o indivíduo devesse se envergonhar. O "filisteu" de Schopenhauer e de Heine, o "burguês" de Flaubert, o "homem mediocre" de Ingenieros, o "homem domesticado" de Lombroso, o "equilibrista" de Bovril, o "indiferenciado" de Ribot, o "perfeito pai de família" de Rojas, o "Babbitt" de Sinclair Lewis, o "homem vulgar", o "boss rapaz", são expressões com que se tem procurado ridicularizar unı dos aspectos da normalidade --- a adaptação ao grupo social.

$\mathrm{Na}$ caracterização de Ingenieros, o homem normal está personificado pelo homem da massa, "o que nos rodeia aos milhares, o que prospera e se reproduz no silêncio e na treva"; é o homem sem idéias, sem personalidade, por essência imitativo, apto a viver como carneiro de rebanho, refletindo a rotina social, aecitando os preconceitos e dogmas úteis à sua condição doméstica; a alma dêsse homem medíocre não tem nada de espontaneidade, é um reflexo da alma da sociedade em que vive, porque a característica dêste homem é imitar a quantos o rodeiam, pensar com a cabeça alheia, e ser incapaz de formar concepções e ideais próprios; dêste modo, êle é o espírito conservador do grupo, interessado em manter os seus hábitos, que lhe amenizam o esfôrço de viver.

Nessa literatura pseudo-científica o yue se nota é uma grande confusão de valores. As descrições apresentadas limitam-se a observações superficiais, a que falta muitas vêzes perfeita objetividade, e que deixam transparecer 
uma certa atitude emocional de crítica e desprêzo, que não se coaduna com o espírito da ciência. 0 "homem mediocre" de Ingenieros não está suficientemente estudado para que possamos concluir se se trata simplesmente de um oligofrênico, incapaz de contribuição maior ao grupo social, devido às suas limitaçōes naturais, ou de um neurótico, inibido pela necessidade de adaptar-se desde criança às vicissitudes de tôda a ordem, e incapaz de opor-se mesmo às exigências mais absurdas do ambiente, sob pena de entrar em pânico e não saber como resolver a ansiedade.

Outra confusão muito freqüente na literatura pseudo-científica, que também afeta a compreensão do problema da normalidade, é a que se estabelece em tôrno de genialidade e neurose. Os biógrafos dos homens superiores têm descoberto em alguns dêles traços neuróticos bem evidentes, o que, entretanto, não autoriza a postular a igualdade entre gênio e neurótico. São duas condições diversas em si mesmas, que às vêzes coexistem no mesmo indivíduo devido a razões que começam a ser averiguadas. Os neuróticos, entretanto, usam essa coexistência, erigida em generalização, como um recurso espúrio para fortificarem o ego enfraquecido. Essa confusão lamentável explica o aparecimento de uma série de livros e artigos psendo-literários e pseudo-científicos, de títulos que fascinam qualquer neurótico, como, por exemplo, "Orgulhe-se de sua Neurose", e outros como tais.

Dentro da própria psiquiatria, o conceito da normalidade tem sofrido deformações de tôda a ordem. Morel, representante máximo da doutrina da degeneração, considera como normal apenas o exemplar específico original do homem, em todo o seu primitivismo, ainda não "degenerado" pelo processo da civilização. Isto corresponde mais ou menos à ficção, popularizada por Jean Jacques Rousseau, do homem liberto, vivendo em contacto com a natureza, admirável na sua espontaneidade e pujança.

Tão pouca é a atenção dadã ao problema da normalidade pelos demais psiquiatras, que para concluirmos o conceito de muitos dêles, temos que inverter os têrmos das definições apresentadas para a loucura. Normal, para Locke e Lauret, é o homem que acerta. Para Lemoine, normal é o indivíduo que pensa e atua como os demais. Binet e Simon dizem: "E' o que conserva um bom equilíbrio mental e revela-se capaz de adaptar-se ao meio ambiente". De acôrdo com Dupré, normal é o homem que não está sob qualquer influência mórbida, que não comete atos estranhos, imotivados e perigosos para êle e os demais. Otto Lenghi, impregnado da orientação organicista, diz que o normal é o que não apresenta nenhuma alteração da personalidade psíquica, dependendo de alguma anomalia ou processo mórbido cerebral. Para Garnier e Santin Rossi, pode-se falar em normalidade no caso dos indivíduos que não apresentam nenhuma detenção no desenvolvimento, desvio ou enfraquecimento das faculdades mentais, correspondente a uma entidade mórbida definida, que são capazes de ter consciência e exercer voluntàriamente os direitos e obrigaçôes estabelecidos pelas leis.

A situação atual, portanto, em relação ao problema da normalidade psicológica, é a seguinte. Alguns, principalmente os que se deixam orientar 
pela mentalidade psicanalítica ortodoxa, negam-na simplesmente. Outros, adotando uma atitude pseudo-científica, confundem-na com a covardia, com a passividade, que são traços decididamente neuróticos. Outros negam ao homem civilizado, trabalhado pelas fôrças culturais, o direito de ser normal. E a maioria dos psiquiatras clínicos define a normalidade por simples exclusão da neurose ou psicose. Tudo isso indica o grande desconhecimento do homem normal. Por isso mesmo as definições propostas até o momento são pouco explícitas, por demais gerais, abstratas, teóricas, absurdas, e limitam-se apenas à superfície ou aparência dos fatos, sem procurar penetrar na estrutura psicológica mais profunda.

Conforta-nos um pouco poder registrar aqui o conceito explanado por Nerio Rojas na sua "Psiquiatria Forense", indicador de um esfôrço produtivo para a compreensão do problema, quando se exprime do seguinte modo: "Dentro das variações individuais e das oscilações fisiológicas naturais no mesmo indivíduo, devemos considerar como homem normal mentalmente aquêle que aprecia com exatidão tôdas as formas acessíveis da realidade para atuar com inteligência no meio ambiente, promovendo uma adaptação ativa, lógica e útil a fatos, coisas e pessoas. Como se vê, trata-se de uma normalidade prática, e não da normalidade ou saúde ideal, que representa mera abstração. Tudo isso efetua-se espontaneamente dentro de um equilíbrio dinâmico, variável e natural, sem auto-consciência dos seus mecanismos, mas com crítica vigilante dos seus desvios".

\section{DIFERENTES ASPECTOS DA NORMALIDADE PSICOLOCICA}

Qualquer esfôrço no sentido da sintetização de um conceito de normalidade deve tomar em consideração os variados aspectos da vida psicológica. Não se pode limitar apenas ao nível da inteligência e à análise psicométrica dos processos mentais, mas considerar igualmente estruturas mais sutis, que dizem respeito à dinâmica emocional e afetiva. Outro cuidado que se impõe é evitar julgamentos apressados feitos na base apenas da observação da aparência exterior e da conduta explícita. Só depois de compreendermos o modo pelo qual o equilíbrio pessoal está organizado, nos assegurarmos da estabilidade relativa dêsse equilíbrio, quando pudermos avaliar a qualidade produtiva dos ideais do indivíduo, as suas potencialidades e capacidades de realização, poderemos nos exprimir com certa segurança quanto à normalidade de um indivíduo. Só quando a conduta explícita e implícita se revelarem uníssonas, é possível falar em normalidade, que requer em si mesma uma harmonia total e profunda, uma ordem ampla e complexa, que não é conferida apenas por um órgão ou função determinada, nem sòmente por um dado aspecto da vida psicológica, mas pela conjunção feliz de diversas condições parciais, que se compensam inùtuamente. 0 aspecto puramente formal e aparente pode representar apenas uma atitude artificial, seja conscientemente fraudulenta ou convencional, seja como recurso neurótico de ajustamento, assumida por obrigação, conveniência, am- 
bição, ou qualquer outra motivação espúria, que tantas vêzes contamina a personalidade humana.

Não resta dúvida de que um dos fatôres primordiais no diagnóstico da normalidade é representado pelo desenvolvimento suficiente e atividade adequada da inteligência. Só a consideração dêste elemento exclui ipso facto os oligofrênicos, os psicóticos, e todos os portadores de estados que se traduzem por acentuada insuficiência, desvio ou perturbação das funções intelectuais pròpriamente ditas.

Não basta, entretanto, o funcionamento intelectual satisfatório; a êste se deve associar uma organização afetivo-emocional, não só explícita na con. duta, mas como realidade íntima, caracterizada por equilíbrio. A normalidade reveste ainda um aspecto ético, que exige a presença das virtudes humanas, sem as quais as próprias potencialidades intelectuais adquirem aspecto estéril. A firmeza do caráter, a dignidade pessoal, a retidão, a lealdade, o que se chama nobreza de sentimentos, o bom senso, a capacidade de vencer honestamente os obstáculos da vida e reafirmar-se como elemento do grupo são fatôres que devem pesar obrigatòriamente na balança, quando pesamos a normalidade. Em uma palavra, é na estrutura do caráter individual que encontramos as bases para o diagnóstico da normalidade psicológica. Encontramo-nos, portanto, em frente de uma dupla tarefa: distinguir a estrutura do caráter neurótico da estrutura do caráter normal.

A conduta explícita adequada é um bom indicador da normalidade, ainda que não baste para defini-la ou afirmá-la. As neuroses hem controladas e os psicopatas inteligentes passariam incólumes neste exame superficial. A conduta do indivíduo normal é a conseqüência natural do dinamismo psicológico sadio. Se houver concordância entre os planos superficiais e profundos da vida psicológica, poderemos dizer, como no Evangelho de São Mateus: "Pelos seus frutos os conhecereis. Porventura colhem-se uvas dos espinhos ou figos dos abrolhos?"

Antes de entrarmos pròpriamente na apreciação da estrutura caracterológica normal e distiıguíla da neurótica, diremos que o indivíduo normal, em face da vida, age como o jogador honesto, que não recorre a truques e falcatruas, sem tortuosidades, sem voracidades incontidas, simplesmente porque prescinde de recursos espúrios para lidar com a realidade. Ele tem capacidade para vencer, e é perfeitamente consciente das suas possibilidades e das suas limitações, que aceita.

\section{CONDUTA EXPLICITA E NORMALIDADE}

Com certas reservas, a conduta é o indicador mais imediato e prático da normalidade psicológica. Um dos pontos que caracterizam a conduta normal é a sua consistência e regularidade, o que permite a previsão e compreensão das ações individuais. $O$ anormal conduz-se em face das circunstâncias com reações imprevistas, adotando normas próprias, incompreensiveis a uma observação superficial. O que autoriza a falar desde logo, ao primeiro contacto, em anormalidade, no caso dos psicóticos, é precisamente 
a qualidade imprevista e paradoxal de sua conduta, o que explica a dificuldade em conservá-los no ambiente social, e a reação geral de receio que êles despertam nos demais.

Portanto, se pensarmos em têrmos de conduta explícita, num plano relativamente superficial, a normalidade pode ser definida como a capacidade de reagir às condições ambientais de modo natural, comum, regular e previsível. Nessas condiçõos, o estudo de um pequeno período da vida individual nem sempre é suficiente para que se possa afirmar a normalidade. Se, entretanto, grande parte da história vital se revela caracterizada por harmonia, regularidade de conduta, produtìvidade, adaptabilidade, e relações favoráveis com os circunstantes, possuímos preciosas indicações para admitirmos a hipótese de normalidade; estamos mesmo em condições de prever até certo ponto quais serão as reações do indivíduo em face de diferentes situações.

Principalmente as reações pessoais aos estímulos e situações desfavoráveis constituem valiosos indicadores em relação ao ponto que nos interessa. Mesmo respeitando as diferenças individuais, o modo de controlar as situa. ções penosas da vida, de procurar modificá-las quando é possível, e adaptar-se a elas até certo ponto, preservando o equilíbrio pessoal, é característico na normalidade e diferente da anormalidade. Os psicóticos refugiam-se na irrealidade, os neuróticos perturbam-se, e os psicopatas degradam-se, quando atravessam momentos difíceis que redundam em insatisfação pessoal. Enquanto que as dificuldades reais são tomadas nas suas proporções objetivas pelos indivíduos normais, os neuróticos agigantam, pelas repercussões subjetivas, o vulto da realidade, e sentem o seu equilíbrio ameaçado. Os normais fortificam-se aos embates; os neuróticos e psicopatas tornam-se fracos e pusilânimes, usando mais que nunca os seus mecanismos de defêsa, que tornam a sua conduta tortuosa e imprevisível.

O sentido moral da conduta é um outro característico da normalidade. Este é um ponto que tem sido bastante descurado até o presente. Sem êste aspecto, faltaria ao quadro da conduta normal algo que a faz objeto da admiração dos que a podem admirar. "A beleza moral" - escreve Alexis Carrel no seu livro "O Homem, êsse Desconhecido" ...- "é um fenômeno excepcional e inolvidável. Quem o haja contemplado, una vez que seja, nunca mais esquece o seu aspecto. $E^{\prime}$ uma forma de beleza muito mais impressionante do que a beleza da natureza e da ciência. Confere aos que possuem seus dotes divinos uma fôrça estranha e inexplicável. Aumenta o poder intelectual. Estabelece a paz entre os homens. Mais do que a ciência, a arte e os ensinamentos religiosos, a verdadeira beleza moral é a base da civilização".

Durante a última guerra, nos campos de concentração nazistas e jáponêses, grupos de indivíduos viram-se sujeitos a situações verdadeiramente experimentais, que permitiram observar o comportamento humano ante as privações mais duras. Respostas francamente psicóticas não faltaram; soluções neuróticas multiplicaram-se. Os que sofriam de uma hipotrofia do aspecto moral e ético da personalidade, como os psicopatas em diferentes 
graus, manipulavam as realidades sem qualquer respeito ao direito dos companheiros, com a única preocupação de obter a máxima satisfação para os próprios apetites. Mas os relatórios dos psiquiatras militares encerram também páginas dignas de aprêço e admiração sincera, com a história de muitos heróis desconhecidos, que, embora encarassem a realidade com objetivismo, e estivessem legìtimamente preocupados com a conservação da própria vida, não levaram o lema de "Salve-se quem puder" aos extremos do egoísmo desenfreado, conservando interêsse pelos companheiros e o respeito e estima próprios.

O desequilíbrio momentâneo, provocado numerosas vêzes no decorrer do curso vital pelas situaçoes particularmente difíceis, exige um reajustamento da dinâmica individual, às vêzes em bases bem diversas das anteriores. 0 modo pelo qual se resolve o conflito de realidade, a sua maior ou menor persistência, depende do eco que desperta dentro do indivíduo, da quantidade de ansiedade liberada, e dos mecanismos de adaptação implicados no ajustamento. O tipo de solução dado ao problema e o equilíbrio dinâmico final são pontos a tomar em consideração na avaliação da normalidade.

Insistiremos, entretanto, que a avaliação das aparências não é nunca suficiente para um diagnóstico exato. Quando falamos em aspecto moral e ético da conduta humana, estamos nos referindo não apenas a realidades aparentes, mas à organização intrínseca, real, que orienta a conduta normal e prescinde de escamoteações e artifícios. Há, por exemplo, indivíduos que apenas agem de modo aprovado pelos cânones sociais, quando estão certos de que estão sendo observados por uma pessoa de cuja boa opinião dependem; trata-se, nesses casos, de uma pseudo-moralidade, apenas para uso externo e com caráter de oportunismo. Outros levam a vida tôda preocupados sòmente com o que "os outros" pensam dêles. Agem bem, aparentemente, por inteligência, por habilidade, mas se pudessem exprimir em linguagem clara o que vive dentro dêles, assistiríamos, como nos contos da Carochinha, saírem cobras e sapos de suas bôcas. Há ainda os que se guiam pela máxima "Façam o que eu digo e não o que eu faço"; êsses são os moralizadores desmoralizados. Tudo isso indica que pode haver conhecimento moral e ético de tipo intelectual, sem uma organização dinâmica emocional e afetiva que lhe sirva de base. Como se trata de uma atitude artificial, mantida à custa de certo esfôrço consciente ou inconsciente, podemos estar certos de que a moralidade dêsses indivíduos resume-se numa farça, que, ou não é mantida de modo constante, ou provoca uma situação de verdadeiro esgotamento.

Dentro dessa ordem de idéias, devemos estar preparados para fazer face a uma realidade um tanto desagradável: se a normalidade fôr medida tanto pelo desenvolvimento intelectual como pelo aspecto moral e ético, vamos começar a verificar quão medíocre é o nível de dignidade da maior parte da humanidade, e quão poucos são os homens que possuem um desenvolvimento razoável das chamadas virtudes cristãs. Resta-nos o consôlo de poder afirmar que existem homens cuja vida se caracteriza por uma orienta- 
ção honesta, homens que podem jogar o jôgo limpo, o que afinal de contas constitui prova de que o tipo normal, mesmo com as exigências que estão sendo apresentadas para o seu diagnóstico, não constitui abstração ou ideal.

A grande desproporção entre o desenvolvimento da inteligência e do aspecto moral do homem da nossa cultura é incontestàvelmente um dos fatôres do desequilíbrio social hodierno. Perdidos os valores éticos das idades passadas, enfraquecido o poder controlador da religião, o homem, jogado numa civilização capitalista, que exalta os bens materiais, faz-se mercenário, e procura convencer-se a si mesmo de que acumulando fortuna e prestígio consegue mascarar o profundo sentimento de insegurança que o tortura, e manter certo grau de estima própria. Sem conhecer a si mesmo, sem compreender que a sua grandeza ou a sua miséria dependem de fôrças inerentes a êle próprio, o homem do nosso século, orgulhoso de haver dominado a natureza, sente-se pequeno e miserável ante as fôrças sociais que êle mesmo, no seu profundo desconhecimento próprio, preparou e mantém. Isolado da natureza pela evolução psicológica, êle assiste à limitação do próprio ego, e sente-se cada vez mais irremediàvelmente só, porque, admitidas as exceções, não consegue aproximar-se dos seus semelhantes, separado que está por hostilidades recíprocas e mêdo de parte a parte.

A realidade triste da maioria dos homens do nosso grupo social levou certos pensadores a generalizarem a fórmula neurótica como condição natural do homem, e a referir-se a êle como "Homo lupus hominis", expressão subscrita por Freud no seu livro tão impregnado de pessimismo, "A Civilização e seus Descontentamentos". Assim, acusa-se o homem civilizado de mau, quando, na realidade, trata-se mais de infelicidade e de neurose, do que pròpriamente de maldade. $\mathrm{O}$ fato de que a neurose esteja muito difundida não significa que ela constitua a condição natural do homem, o destino a que êle não pode escapar. $O$ fato de que nas culturas medievais todos os indivíduos fôssem parasitados por piolhos não quer dizer que a pediculose seja o estado normal do homem. 0 homem forte e capaz, ciente do próprio valor, conhecedor das suas possibilidades e limitações, aquêle cuja vida não é orientada por agressões desenfreadas nem sempre conscientes, o que pode confiar nos seus semelhantes sem mêdos, o que, em suma, não se sente só, o que se pode entregar ao prazer da dependência emocional sem anular-se ou sentir-se ameaçado em sua independência - o homem normal, em uma palavra - não precisa ser mau para vencer, e não o é. Consegue dar um sentido produtivo à sua vida, sem precisar destruir os seus semelhantes.

Talvez a solução para a tremenda crise moral que a humanidade atravessa esteja na revelação, ao próprio homem, das suas necessidades emocionais e afetivas, das suas potencialidades psicológicas, das suas limitações naturais, às quais se deve conformar, para que, consciente de si mesmo, êle possa saber o que quer, aprender a dirigir-se no sentido da obtenção de objetivos reais, valendo-se de recursos honestos e leis, que lhe permitem prescindir de fachadas, e abandonar ideais espúrios que o escondem de si mesmo, enchem-no de vergonha consciente ou inconscientemente, e abalam cada vez maje a sua segurança. 
A psicanálise freudiana, ao postular a agressão como instinto, e o homem como um feixe de necessidades instintivas que se chocam com as convenções sociais, chegou a conclusões absolutamente pessimistas quanto às possibilidades de aperfeiçoamento humano.

O novo pensamento dinâmico, aliando dados antropológicos, sociológicos e psicológicos recentes, está chegando a uma imagem mais satisfatória do homem, capaz de permitir atitudes construtivas. O mal não reside pròpriamente na natureza intrínseca do homem, mas na sua neurose, que é razão ao mesmo tempo da sua maldade e da sua tortura. A neurose representa recurso de que lança mão o indivíduo para assegurar o seu equilíbrio ameaçado e continuar vivendo apesar dos pesares. Como geralmente a estrutura neurótica do caráter se esboça já nos albores da vida, devido às condições emocionais desfavoráveis a que é exposta a maioria das crianças, é de esperar que o aperfeiçoamento da técnica de educação infantil redunde pelo menos na atenuação dos dramas e conflitos humanos, cuja ação corrosiva enfraquece o ego e explica as reações neuróticas.

Não somos exageradamente otimistas, embora não nos sintamos irremediàvelmente pessimistas. Olhamos com a possível objetividade para o panorama atual, revestidos do espírito que orienta o pensamento dinâmico contemporâneo. Fazemos nossas as palavras dos irmãos de Goncourt: "A bon. dade que resiste aos homens e aos desenganos, a bondade que tenho encontrado em estado de pureza em poucas pessoas durante a minha vida, é o bem mais excelso que há no homem".

Fazemos, pois, questão de estabelecer a moralidade intrínseca como um dos atributos genuínos da normalidade, e lastimar a escassez das provas psicológicas para avaliar êste aspecto delicado e supcrıor da vida humana, enquanto abundam os testes para medir a capacidade intelectual. Este estado de coisas indica a precariedade do ideal humano nos tempos que correm, pela supervalorização dos fatôres intelectuais, e esquecimento do aspecto moral e ético.

\section{O CARATER FLEXIVEL DA NORMALIDADE}

A capacidade do homem normal de manter-se em estado de equilíbrio é uma característica da condição. Este equilíbrio nada tem de estático; desloca-se a todos os momentos, exigindo constantes ajustamentos, de acôrdo com as circunstâncias, que variam. Essa flexibilidade do indivíduo normal não indica fragilidade, nem instabilidade, nem morbidez. A estabilidade absoluta, a rigidez, esta sim, é anormal, pois impede as freqüentes e necessárias adaptações às condições sempre novas da vida, que é em si mesmo movimento. $\mathrm{O}$ compulsivo pode agir de modo aparentemente adequado, com absoluta regularidade, usando sempre os mesmos processos de manipular a realidade, com relativo êxito, sem que por isso mereça o diagnóstico de normalidade. Se a realidade algum dia fôr de tal ordem que exija flexibilidade e requeira ajustamentos freqüentes em novas hases, é quase certo 
que o compulsivo sucumbirá à ansiedade desencadeada pela necessidade de abandonar os seus recursos sempre uniformes. 0 normal, ao contrário, pode adaptar-se às novas situações, compensando, sem ansiedades desnecessárias, o desvio inesperado do seu centro de gravidade.

Enquanto que a normalidade aparente ou falsa é sempre o resultado de um esfôrço constante e sobre-humano de manter o equilíbrio, a normalidade verdadeira impressiona como algo natural, que brota sem esfôrço, em. bora, dado o caráter das realidades sociais, não possa prescindir de um certo trabalho de vontade para manter as pautas da conduta num plano de dignidade.

Desde que a sua base é um equilíbrio dinâmico, conseguido pela conjunção de várias fôrças, a normalidade não pode ser simples, permanente no seu aspecto, uniforme e única. Ela comporta várias categorias, vários niveis, matizes e tipos. Aparece às vêzes mais perfeita, outras vêzes mais imperfeita; pode apresentar-se vulgar e comum, e distinguir-se como superior e genial. Nem sempre ela é impecável, e não podemos negá-la pela simples presença de uma pequenina fraqueza, de um pouco de originalidade, que distingue um indivíduo de ontro. (Os normais têm os seus maus nomentos, como os anormais as suas boas horas. Por isso mesmo, não é um sinal certo de anormaliade o fato de incorrer o indivíduo numa irregularidade esporádica da conduta; como também não autoriza o diagnóstico de normalidade por si só uma conduta explícita isenta de falhas. A pessoa normal, segura de si mesma, pode sem ansiedade dar-se o prazer de cerlas extravagâncias inocentes, que o neurótico, inseguro e preocupado em manter a sua estima pessoal e a dos outros, não se pode permitir.

\section{ASPECTO IMPLICITO DA NORMALIDADE}

Caracteriza a normalidade, no plano intelectual, não apenas um certo volume de inteligência e ausência de alterações dos diferentes aspectos da vida mental, como principalmente o modo pelo qual a inteligência é usada na solução dos problemas de adaptação. Não se trata apenas de perfeita clareza mental e de lógica, mas antes do sentido da atividade intelectual, o "espírito" que a orienta, ou, melhor, das fôrças emocionais que a impulsionam. O pensamento dos compulsivos pode ser robusto, sem que isto autorize o diagnóstico de lormalidade. Certos psicopatas deixaram nome nos anais da história pelo caráter destruidor da sua inteligência, e nem por isso escaparam ao diagnóstico retrospectivo. Nos paranóides vemos, sôbre pre. missas falsas, orientadas catatìmicamente, como por exemplo a crença de que conspiram contra êles, um enrêdo mental lógico e claro, que denota em alguns casos grandes reservas intelectuais e cultura.

O paranóide, o psicopata, o compulsivo, como de modo geral todos os que atuam sob a inspiração de um caráter neurótico, fogem à condição intrínseca da normalidade intelectual, que é usar a inteligência num sentido construtivo; êles a delapidam inùtilmente e fracassam quando têm de en- 
trar em relação um pouco mais estreita com as coisas e sêres do mundo, que nunca chegam a compreender, no sentido mais profundo da palavra. Algumas vêzes 0 indivíduo, levado pela sua neurose, simplesmente não se aproxima do mundo, ou o faz de modo indiferente. No caso da personalidade normal, ao contrário, um fenômeno, um objeto, um animal, ou outra pessoa torna-se assunto de cogitação intelectual, pela interêsse que desperta; nessas condições, para o indivíduo normal, o mundo não se resume a um palco povoado de coisas inanimadas, manipuladas por êle apenas de acôrdo com as suas necessidades emocionais, e sujeitas a um simples jôgo intelectual. No caso da normalidade, o pensamento, a elaboração intelectual é determinada pela reação total do indivíduo ao objeto, e guarda estreitas relações com a atitude emocional daquele. Essa atitude emocional deve ser de tal ordem que permita respeitar a realidade, sem deforná-la nos seus elẹmentos essenciais. Sem objetividade e certa dose de subjetivismo não se pode falar em normalidade. A pessoa normal é afetada pelo mundo exterior, ao qual reage espontâneamente, ao mesmo tempo que consegue ver e sentir a realidade como ela se apresenta, e não como desejaria que fôsse. A objatividade concebida nesses têrmos não sịgnifica de modo algum indiferença, como de outro lado subjetividade não quer dizer paixão.

Esse aspecto da normalidade, ou seja, a polaridade entre objetivismo e subjetivismo, é particularmente importante para os que trabalham com problemas humanos. Sem um certo grau de interêsse pelos semelhantes, não é possivel vencer as vicissitudes inerentes a êsse tipo de trabalho. Se, entretanto, as emoções individuais, quer positivas, quer negativas, interferirem excessivamente no trabalho de análise e de reconstrução do paciente, o pensamento tende a degenerar em especulações, críticas, fantasias, que viciam a compreensão da realidade. Convém frisar que objetividade não significa indiferença ou afastamento, mas antes aproximação, interêsse e respeito pela realidade. $O$ perigo não está no interêsse do indivíduo pelo fenômeno ou pela pessoa, mas no interêsse vicioso, que mascara intençōes neuróticas e é incompativel com a verdade.

Dentro da polaridade referida (objetivismo-subjetivismo), o objeto de estudo tanto é visto no seu conjunto como nas partes que o constituem. A consideração do todo, com esquecimento das partes, como também a exces. siva atenção aos detalhes, a observação de aspectos parciais do fenômeno sem a preocupação do conjunto, sacrifica certamente a valorização exata dos fatos; nem uma nem outra atitude revela respeito pelo objeto.

Como é fácil compreender, o sentido ou o "espírito" da atividade intelectual, que vimos analisando, guarda íntimas relações com a fórmula emocional do indivíduo, ou seja, com a estrutura do seu caráter.

Ainda que não seja exclusivamente no terreno do amor que a realidade emocional de cada um se póe de manifesto, é incontestàvelmente nesse terreno que a normalidade sofre seu teste mais acurado. Podemos dizer que tôdas as pessoas amam, ou pelo menos pensam que amari, a seu modo, mas que o amor normal é privilégio apenas de alguns. A maioria julga que nada há mais fácil de amar e, quando infelizes, limitam-se a explicar a fa- 
lência própria pela falta de sorte em encontrar um parceiro adequado. A análise da situação dêsses "caiporas" no amor revela, em muitos casos, que a culpa não é exclusivamente do parceiro, que se trata de uma verdadeira incapacidade de amar, ou seja, de uma deturpação inconsciente dêsse sentimento, cujo sinal positivo se enfraquece pela interferência de variadas fôrças negativas.

A dificuldade em definir o amor reside, em grande parte, no fato de que cada um sente êsse estado diferentemente, de acôrdo com o seu modo de relacionar-se às coisas e amar aos sêres: Há quem chame uma relação de pura dependência, amor; outros acham que amam quando simplesmente desejam a posse de um objeto; o que se deixa explorar declara-se apaixonado, e o explorador também não trepida em dizer que está amando. A verdade é que todos durante a vida conjugam o paradigma da primeira conjugação, mas poucos o fazem de modo predominantemente construtivo. Deve ficar entendido que o verdadeiro amor é sentimento bastante específico, e que a sua realização, dada a situação neurótica de nossa cultura, é privilégio de poucos. O próprio amor materno, que tem sido tão exaltado através dos tempos, presta-se a deformaçóes de tôda a ordem, no zêlo e carinho misturando-se às vêzes dominação tirânica, exigências absurdas, absorção egoista, proteção excessiva, etc.

Erich Fromm, no seu livro "Man for Himself", caracteriza o que êle chama "amor produtivo", que condiz com o nosso modo de entender o "amor normal"; seus elementos básicos são: ternura, responsabilidade, respeito, conhecimento da pessoa amada. "Ternura e responsabilidade", diz Fronm, "denotam que o amor é lima atividade e não uma paixão que domina o indivíduo". Quem ama no sentido real da palavra preounpa-se com o bemestar da pessoa amada e sente-se responsável pelo seu confôrto e felicidade. Sem respeito e conhecimento da realidade do objeto da estima, o amor deteriora em exploração, dominação e posse. Respeito, diz Fromm, não significa mêdo e veneração; denota antes a capacidade de ver a pessoa como ela é, ter consciência da sua individualidade, e tratá-la como tal, reconhecendo o seu direito de desenvolver as suas potencialidades. Só amamos uma pessoa quando a conhecemos e a aceitamos com seus defeitos e qualidades; sem êste conhecimento, $u$ amor degenera em farça, pois que o objeto perde a sua realidade para ajustar-se ao ideal subjetivo do amante.

Essa descrição tanto se aplica ao amor sexual como às demais relações afetivas, seja o amor entre irmãos, o amor filial, o afeto dos pais pelos filhos, a amizade, a dedicação à ciência, o cultivo das artes, e tôda a escala de sentimentos ao qual se aplica o têrmo amor.

E' precisamente no modo de relacionar-se às coisas e sêres do ambiente que a normalidade se define e se separa da anormalidade. A atitude, por exemplo, em face de uma simples taça de sorvete pode assumir infini- 
tas nuances. A personalidade adulta, emocionalmente madura, encara-a como um prazer alimentar simples, uma coisa que é saborosa, particularmente agradável num dia de calor, e absolutamente lícito. Para um adulto inseguro, o sorvete que lhè é oferecido por outra pessoa pode ter o valor simbólico de uma prova de afeto da mais alta importância. A gula, a voracidade, como o desgôsto, o desinterêsse ante uma taça de sorvete indicam que as relações do indivíduo com êste simples objeto estão prejudicadas; essa atmosfera emocional, que se dinamiza ante êste banal teste de realidade, naturalmente não se limita a êsse incidente de pouca significação, mas interfere em outras relações de maior importância. Passando por formas intermediárias (amor a um quadro, a uma casa, a uma sinfonia, a um animal), chegamos às formas mais elevadas do amor: o amor à arte, à ciência, aos semelhantes, e ao tipo mais íntimo da relação afetuosa, o amor sexual. (Não chamamos aqui amor à simples relação sexual, que apenas assegura a satisfação do instinto biológico).

A intimidade, a aproximação estreita dos indivíduos requerida pelo amor sexual faz com que êste seja, na realidade, o indicador mais preciso, ainda que não único, da normalidade. Se o mêdo orienta 0 indivíduo nas suas relações com o mundo, é de prever que êle não possa se entregar de coração aberto ao intercâmbio emocional implícito no amơr. $O$ essencialmente agressivo, com tendências à exploração, não abre certamente unı exceção para a pessoa "amada". O inseguro, que precisa de constantes provas de aprêço para a manutenção da sua própria estima, exigirá do parceiro por vários modos uma atitude de adulação constante. 0 dependente achará recursos, nem que seja a doença, para fazer-se merecedor de compaixão e agarrar-se ao objeto do seu "amor" como o parasito do hospedador.

Essas atitudes, reveladas no terreno do amor sexual, não se limitam apenas ao campo erótico, mas caracterizam o indivíduo nas suas relações com o mundo, quaisquer que sejam os aspectos assumidos pela realidade. Há tanta correlação entre os diversos planos da atividade individual, que a observação bem orientada de um só aspecto do comportaniento pode permitir, em muitos casos, avaliação bem aproximada da conduta pessoal em geral. Um observador perspicaz, apreciando as maneiras de uma pessoa das nossas relações à mesa do jantar, concluiu, com bastante exatidão, sôbre qual seria o comportamento dêsse indivíduo nas suas relações conjugais. Há, entretanto, tanta dissimulação, tantos artifícics no comportamento explícito da maioria das pessoas, interessadas em esconder seus interêsses e faltas inconfessáveis, que a simples verificação de boas maneiras em público não autoriza generalizações apressadas, e não é garantia, portanto, do que chamamos normalidade.

A pobreza de atividade é o sintoma mais aparente de organização emocional viciosa; a dinâmica do fenômeno -- como aliás acontece com tôdas 
as atitudes humanas - é sempre complexa, e varia de indivíduo para indivíduo. A atividade, entretanto, por si só, não define a normalidade. A atividade normal traduz a capacidade pessoal de usar as energias num sentido construtivo e realizar as próprias potencialidades, sem que o móvel seja a ansiedade. A hiperatividade pode ser tão neurótica quanto a inatividade, representando nada mais do que um recurso de controlar a ansiedade individual; os seus móveis variam em cada caso. Para o avarento, o invejoso, o ambicioso, o trabalho, longe de obedecer a motivos intrinsecamente construtivos, e representar uma afirmação natural, espontânea, e legítima das potencialidades individuais, degenera em jôgo neurólico. Por isso mesmo, convém, quando queremos diagnosticar a normalidade, analisar o espírito que inspira a atividade, isto é, a fórmula emocional que impele o individuo nas suas realizações. Não é absolutamente necessário que as realizações humanas tenham sentido prático imediato; as atividades teóricas, como o pensamento abstrato, podem indicar maturidade emocional, do mes. mo modo que o trabalho clínico ou a atividade do artífice. 0 sucesso aparente ou a falta dêle não são por si mesmos indicadores exatos de normalidade. $\mathrm{O}$ mundo atual está cheio de indivíduos artificiais, dotados de fachadas atraentes, que conseguem vitórias de prestígio, sem que por isso se sintam menos inseguros, menos ansiados. Excessiva ansiedade pode ser o motivo das suas conquistas sucessivas e do seu fracasso íntimo. Por esta razão, quando pensamos em têrmos de normalidade, devemos estar mais interessados em avaliar a estrutura caracterológica pessoal do que em pesar e medir sucessos e fracassos. Um marceneiro no fundo da sua oficina, levando uma vida honesta e laboriosa ao lado da familia, imbuído do sentimento da própria utilidade, e satisfeito com as formas que tira da madeira, pode ser mais normal do que o homem de negócios vitorioso, que nunca se satisfaz com a altura das pilhas de moedas na caixa forte, ou o brilhante condutor de massas, aplaudido pelas multidões, mas dentro de si mesmo envergonhado dos seus recursos golpistas e receoso dos homens e da má vontade de fôrças ocultas.

Tôdas as considerações acima conduzem muito naturalmente à conclusão de que a última palávra em matéria de normalidade é dada pela organização da estrutura do caráter pessoal. Finalizando, como sumário dos fatos apontados, diremos que o indivíduo adulto normal exibe uma personalidade que se caracteriza por harmonia entre os diferentes planos da organização pessoal. Nessas condições, suas atividades são espontâneas e naturais; sua conduta explícita condiz com as realidades emocionais profundas. Diremos ainda que o indivíduo emocionalmente adulto dá à sua vida 
sentido produtivo, e é capaz de usar tôdas as suas capacidades e desenvolver as potencialidades que lhe são inerentes; êsse processo implica uma consciência relativarıente exata das suas realidades, das suas necessidades, das suas possibilidades e limitaçōes. Acrescentaremos que a personalidade sadia é capaz de manter relação natural e espontânea com o mundo, sem receios injustificados, sem agressões desnecessárias. E' capaz de amar, e portanto de fazer-se amada, numa base de ternura, responsabilidade, respeito e conhecimento recíproco. $E$ dentro da dureza relativa das realidades do mundo atual, fruto da neurose da maioria, o indivíduo normal consegue afirmar-se, e realizar construtivamente o seu destino humano.

Rua Alves de Brito, 12 (Tijuca) - Kio de Janeiro. 